\title{
Relative platelet reduction provides a better pathophysiologic signature of coagulopathy in sepsis than absolute platelet count: A large multicenter elCU database analysis
}

\section{Daisuke Kasugai ( $\nabla$ dkasugai@med.nagoya-u.ac.jp )}

Nagoya Daigaku Daigakuin Igakukei Kenkyuka Igakubu https://orcid.org/0000-0002-8692-3003

\section{Masayuki Ozaki}

Nagoya Daigaku Daigakuin Igakukei Kenkyuka Igakubu

Kazuki Nishida

Nagoya Daigaku Igakubu Fuzoku Byoin

\section{Yukari Goto}

Nagoya Daigaku Daigakuin Igakukei Kenkyuka Igakubu

Kunihiko Takahashi

Tokyo Ika Shika Daigaku

\section{Shigeyuki Matsui}

Nagoya Daigaku Daigakuin Igakukei Kenkyuka Igakubu

\section{Naoyuki Matsuda}

Nagoya Daigaku Daigakuin Igakukei Kenkyuka Igakubu

\section{Research}

Keywords: Intensive care units, platelets, sepsis, thrombocytopenia, mortality, coagulopathy

Posted Date: September 28th, 2020

DOI: https://doi.org/10.21203/rs.3.rs-82685/v1

License: (a) (i) This work is licensed under a Creative Commons Attribution 4.0 International License. Read Full License 


\section{Abstract}

\section{Background}

In sepsis-associated coagulopathy and disseminated intravascular coagulation, the relative platelet reduction may reflect the severity of the coagulopathy. However, there is little evidence to support its clinical significance and most of the coagulopathy criteria in sepsis focus on absolute platelet count. The aim of this study was to estimate the impact of the relative platelet reduction and the absolute platelet count on outcomes in sepsis.

Methods

Multicenter retrospective observational study was performed using the eICU Collaborative Research Database, which includes 335 intensive care units (ICUs) in the United States. Patients with sepsis and with an ICU stay of longer than 2 days were included. The estimated effect of the relative platelet reduction and the absolute platelet count on mortality and coagulopathy-related complications were evaluated.

Results

Of 30,114 septic patients, 26,193 were included in this study. Multivariable mixed-effect logistic regression analysis revealed marked in-hospital mortality risk with more profound degrees of relative reduction in platelet count between day 1 and day 2 , which is independent from the resultant absolute platelet count. Adjusted odds ratio (OR) for in-hospital mortality was 1.28 (95\% confidence interval [Cl], 1.23-1.32); 1.86 (95\% Cl, 1.75-1.97); 2.99 (95\% Cl, 2.66-3.36); and 6.05 (95\% Cl, 4.40 - 8.31) for 20-40\%, 40$60 \%, 60-80 \%$, and more than $80 \%$, respectively, compared to less than $20 \%$ decrease in platelet. Interaction for mortality odds between relative platelet reduction and resultant absolute platelet count was not found $(p=0.33)$. In multivariate logistic regression analysis, the estimated effects of platelet reduction $\geqq 50 \%$ for coagulopathy-related complications were greater than that of platelet counts $\leqq 100,000 / \mu \mathrm{L}$ on day 2 (OR for composite outcome [95\%Cl], 2.03 [1.68 - 2.45] and 1.18 [1.07 - 1.30], respectively).

Conclusion

The magnitude of platelet reduction not only represents mortality risk but also provides a better signature of coagulopathy in sepsis than absolute platelet count, and may, therefore, be more plausible for the criteria of coagulopathy in sepsis.

\section{Introduction}

Sepsis is a major concern in the field of critical care and occurs from an uncontrolled and dysregulated immune response against infection, which causes multiple organ dysfunction (1). For decades, the 
survival rate of patients with sepsis has not significantly improved, despite several randomized control trials (RCTs) on new treatment modalities and improved compliance with treatment guidelines (2-4).

Platelets play an important role in the pathogenesis of sepsis and sepsis-associated mortality $(5,6)$. A decreased platelet count is commonly observed in sepsis and is associated with mortality $(5,6)$. During sepsis, thrombocytopenia is thought to occur due to an increased rate of platelet consumption via multiple pathways [activation of platelet membrane receptors such as toll-like receptor 4 and proteaseactivated receptors $(7,8)$, hemophagocytosis (9) and disseminated intravascular coagulation (DIC) (10) ] rather than decreased platelet production (11). From this perspective, the degree of platelet consumption reflects the pathophysiology and severity of the underlying coagulopathy.

Most international criteria on coagulopathy in sepsis do not consider the relative platelet reduction but focus instead on absolute platelet count (12-15). However, given that the normal range of platelet count is broad, the same level of the resultant platelet count may not imply the same extent of hemostatic derangement. There has been little evidence to support the clinical significance of the percent fall of platelet count in sepsis $(13,16)$. Limited sample sizes and inadequate adjustments for confounders in previous studies make it unclear whether the absolute count or relative reduction is more important. In this context, further research is necessary to understand how the relative platelet reduction and the absolute platelet count affect the outcome of sepsis. The aim of this study was to estimate the impact of the relative platelet reduction and the absolute platelet count on outcomes in sepsis.

\section{Methods}

\section{Data source and study population}

We performed a retrospective observational study using a multicenter database in the United States (The elCU Collaborative Research Database). The database contains stratified random samples of patients (admitted between 2014 and 2015) from data repositories of 335 intensive care units (ICUs) from 208 hospitals located in the United States, amounting to 200,859 ICU admissions in total. Details of the database are described elsewhere (17). Eligible subjects were patients with sepsis at ICU admission. The definition of sepsis is in accordance with the third sepsis definition (1). Specifically, patients with documented or suspected infectious disease, along with the evidence of organ dysfunction (total Sequential Organ Failure Assessment [SOFA] score $\geq 2$ points), were screened $(1,18)$. Those who lacked data on platelet counts at ICU admission, or died, or were discharged from the hospital within 2 days after ICU admission were excluded from the analysis.

We used the REporting of studies Conducted using Observational Routinely collected health Data (RECORD) (19) statements for reporting this study.

\section{Relative platelet reduction and Outcomes}


Relative platelet reduction was calculated from the initial platelet count of day 1 (within 24 hours of ICU admission) and minimum values of day 2 (between 24-48 hours of ICU admission).

The primary outcome was in-hospital mortality. The secondary outcome was coagulopathy-related complications. The coagulopathy-related complications were defined as complications of new hemorrhagic events and thrombotic events after day 2 of ICU admission (Table S1 in additional file 1). If the active diagnosis of hemorrhagic and thrombotic events was recorded before and after day 2 in these patients, the patients were not considered to be experiencing new complications.

\section{Covariates}

Covariates used for the primary model included patient-level variables such as age, sex, body mass index, ethnicity, comorbid conditions indicated by charlson comorbidity index, focus of infection, nosocomial onset of sepsis, severity score defined as the Acute Physiology and Chronic Health Evaluation (APACHE) IV score, number of ICU visits, and types of ICUs (20-22). Hospital-level variables including bed capacity, region of hospital location, teaching status of hospital were also included (23-25).

\section{Statistical analysis}

Continuous variables were expressed as medians with interquartile ranges (IQR) or means and standard deviations (SD), as appropriate. Categorical data were analyzed using $\chi 2$ tests to calculate unadjusted odds ratios.

For the primary analysis, multivariable mixed-effect logistic regression analysis was performed to estimate the mortality odds of each range of the relative platelet reduction (less than 20\%, 20-40\%, 40$60 \%, 60-80 \%$, and more than $80 \%$ ) and absolute platelet count on day 1 (categorization was based on SOFA score). The hospital of admission was used as a random intercept to account for clustering by hospital $(24,25)$. Subgroup analyses were also performed on those who did and did not experience thrombocytopenia, shock, and acute respiratory failure.

To further examine the association between platelet count trajectory and coagulopathy-related complications, multivariate logistic regression analysis was performed to estimate the odds of relative platelet reduction and absolute platelet counts on day 2 for coagulopathy-related complications. Since the incidence of coagulopathy-related complications were relatively rare, we did not adjust hospital-level variables in this model. The cutoff of $\geqq 50 \%$ for the relative reduction and $\leqq 100,000 / \mu l$ for the absolute counts were used based on previous studies (13-15).

For handling missing data, we assumed that missing data were conditional, based on observed covariates (missing at random): multiple imputation was performed with multivariate imputation by the chained equations (MICE) package (26). For continuous, non-normal variables with upper and lower boundaries, we used predictive mean matching. The results of 10 imputed datasets were combined by averaging, and standard errors were adjusted to reflect both within- and between imputation variability. 
For the sensitivity analyses, we repeated our analyses: 1) with the complete case set, 2) using models with additional covariates for adjustment, and 3 ) under alternative criteria of patient selection, to test the robustness of the primary analysis. The alternative model included the following additional covariates, which have the potential to be causally related to the outcome and/or platelet reduction: initial type of antibiotics, heparin administration, and renal replacement therapy. For the alternative cohort, we selected patients with an explicit diagnosis of sepsis (27). All statistical analyses were performed in $\mathrm{R}$ version 4.0.0.

\section{Results}

\section{Characteristics of the patients}

Among 30,114 patients with sepsis, 26,193 (87.0\%) were included in the primary analyses. The flow diagram of the patient selection for each dataset is shown in Figure 1. A total of 3,921 were excluded:

831 (2.8\%) for lack of platelet count information on day 1 and 3,090 (10.3\%) for death or discharge within 2 days. The patient characteristics are summarized in Table 1 and are shown in detail in the table (Additional file 2: table S2). The patients who were older than 60 years on average, were predominantly Caucasian (77.8\%), and predominantly had pulmonary infections (52\%). The median length of hospital stay was 7.4 days (interquartile range, $4.7-12.1$ days) while the in-hospital mortality was $16.7 \%$. New onset of coagulopathic complications after the second day of ICU admissions were relatively rare (thrombotic complications: 139 [0.5\%]; hemorrhagic complications: 145 [0.6\%]).

\section{Relative platelet reduction, absolute platelet count, and mortality}

In the multivariable mixed-effect logistic regression analysis, the adjusted odds ratio (OR) for in-hospital mortality was 1.28 (95\% confidence interval [Cl], 1.23-1.32); $1.86(95 \% \mathrm{Cl}, 1.75-1.97), 2.99(95 \% \mathrm{Cl}, 2.66-$ 3.36) and $6.05(95 \% \mathrm{Cl}, 4.40$ - 8.31) with $20-40 \%, 40-60 \%, 60-80 \%$, and more than $80 \%$, respectively, compared to a less than $20 \%$ decrease in platelets (Table 2). The estimated effect of absolute platelet count on day 2 was relatively small $(\mathrm{OR}, 1.2 ; 95 \% \mathrm{Cl}, 1.18-1.21$; with each increase in hematology component of the SOFA score). Interaction for mortality odds between relative platelet reduction and resultant absolute platelet count was not found $(p=0.33)$. The presence of shock and respiratory failure negatively correlated with the mortality odds of relative platelet reduction $(p<.001$ and $p=0.006$ for interaction, respectively).

\section{Relative platelet reduction, thrombocytopenia, and coagulopathy-related complications}

The result of multivariate logistic regression analysis for predicting coagulopathy-related complications is shown in Table 3. The estimated effects of a platelet reduction $\geqq 50 \%$ for coagulopathy-related complications were greater than that of platelet counts $\leqq 100,000 / \mu \mathrm{L}$ on day 2 (OR for composite outcome [95\%Cl], 2.03 [1.68 - 2.45] and 1.18 [1.07 - 1.30], respectively).

\section{Sensitivity analyses}


The results of the sensitivity analyses are shown in tables S3 (additional file 3 ). The results of the estimated adjusted OR of the platelet drop rate were similar in the complete case analysis; with additional potential risk factors; and in datasets with alternative inclusion criteria.

\section{Discussion}

This is the largest study so far, to evaluate the prognostic impact of both the magnitude of platelet reduction and the absolute platelet count in patients with sepsis. The main findings of this study were as follows: 1) The higher the rate at which the platelets were reduced from day 1 to day 2 , the greater the estimated effect size of the mortality rate increase, and this relationship was independent of the absolute platelet count; and 2) a platelet reduction $\geqq 50 \%$ showed a higher odds of coagulopathy-related complications than that associated with a resultant absolute platelet count $\leqq 100,000 / \mu \mathrm{L}$.

While studies have been conducted so far on patients who develop thrombocytopenia during sepsis, limited data were available in terms of the clinical significance of platelet reduction rates $(13,28)$. The majority of international coagulopathy criteria for sepsis do not include the rate of platelet drop criterion $(12,14,15)$. Gando et al. studied 273 patients with sepsis, and were the first to report the association between crude mortality and the rate of platelet decrease (13). Another study evaluated 1,077 critically ill patients and showed that a platelet reduction rate on day $4 \geqq 30 \%$ predict mortality (28). The results of our study added following value; indicating higher mortality odds with increasing magnitude of platelet drop at day 2 in sepsis, which is independent of the resultant platelet count. As suggested in a previous study, platelet drop may represent the fibrinolytic shutdown in sepsis (29). Our findings that relative platelet reduction showed an increased odds for coagulopathy-related complications more than that observed with thrombocytopenia is consistent with this hypothesis. These findings give full recognition to the significance of platelet reduction rates coagulopathy associated with sepsis.

The severity stratification led to success in showing positive effects of interventions in some previous RCTs in the field of critical care $(30,31)$. In an experimental study, variations in the phenotypes resulted in unstable RCT conclusions (32). When designing clinical trials, platelet drop rate can be useful in grading the severity of coagulopathy in sepsis and in sample size estimation. Furthermore, while using it as a surrogate marker for the development of coagulopathy, preventive interventions for coagulopathy can be assessed. From this context, further study is required to predict rapid platelet drops in earlier phases of treatment.

The current study used a multicenter, large real-world database in the United States with stratified random sampling (17). It provides a robust estimation, not biased by the characteristics and the management of sepsis at specific centers. The results can be generalized to patients with sepsis in various ICU settings in high-income countries. However, this study has several limitations. First, excluding earlier deaths resulted in the selection of patients from the less severe group. For those in the higher early mortality group, it may have been more appropriate to use the earlier timepoint for evaluation, such as the first 3-6 hours. Second, the real-world data did not include further details on coagulation markers (e.g., d-dimer, anti- 
thrombin activity, and plasminogen activator inhibitor-1), which did not allow for further evaluation of the usefulness of platelet drop in comparison with these markers. Lastly, the severity of complications was not reported. Prospective studies to evaluate the incidence and severity of coagulopathic complications in those high-risk populations (i.e., with rapid platelet drops), may be warranted.

\section{Conclusion}

Our findings suggest that identifying the magnitude of the relative reduction in platelet count was better for stratify the risk of mortality and coagulopathy-related complications compared to using the resultant absolute platelet count. This value compared to the platelet count, may therefore be a more plausible criterion for assessing coagulopathy in sepsis.

\section{Abbreviations}

Intensive care units (ICUs)

Disseminated intravascular coagulation (DIC)

Sequential Organ Failure Assessment (SOFA)

REporting of studies Conducted using Observational Routinely collected health Data (RECORD)

Acute Physiology and Chronic Health Evaluation (APACHE)

Randomized control trials (RCTs)

\section{Declarations}

\section{Ethics approval and consent to participate}

Data used in this study were de-identified and released under the Health Insurance Portability and Accountability Act (HIPAA) safe harbor provision. The re-identification risk was certified as meeting safe harbor standards by Privacert (Cambridge, MA) (HIPAA Certification no. 1031219-2). Therefore, the ethical approval statement by the institutional review board and informed consent were waived for this study.

\section{Consent for publication}

Not applicable

\section{Availability of data and materials}

The data used for this manuscript was requested through and available from the eICU Collaborative Research database: https://eicu-crd.mit.edu/. 


\section{Competing interests}

The authors declared no potential conflicts of interest with respect to the research, authorship, and/or publication of this article.

\section{Funding}

This research did not receive any specific grant from funding agencies in the

\section{Authors' contributions}

DK, and MO were responsible for the study concept and study design. Data extraction was undertaken by DK and MO. DK, KN, KT, and SM responsible for data analyses. The first draft was written by DK. KN MO, YG, KT, SM and NM provided comments and review of draft analyses. All authors reviewed and approved the final version of the manuscript.

\section{Acknowledgments}

None

\section{References}

1. Singer M, Deutschman CS, Seymour CW, Shankar-Hari M, Annane D, Bauer M, et al. The third international consensus definitions for sepsis and septic shock (Sepsis-3). JAMA.2016;315:801-10.

2. Luhr R, Cao Y, Söderquist B, Cajander S. Trends in sepsis mortality over time in randomised sepsis trials. A systematic literature review and meta-analysis of mortality in the control arm, 2002-2016. Crit Care. 2019;23:241.

3. Seymour CW, Gesten F, Prescott HC, et al. Time to treatment and mortality during mandated emergency care for sepsis. N Engl J Med. 2017;376:2235-44.

4. Hume PS, Varon J, Englert JA, Hurwitz S, Klompas M, Baron RM, et al. Trends in "usual care" for septic shock. Infect Control Hosp Epidemiol. 2018; 39:1125-6.

5. Vardon-Bounes F, Ruiz S, Gratacap MP, Garcia C, Payrastre B, Minville V, et al. Platelets are critical key players in sepsis. Int J Mol Sci. 2019;20:3494.

6. Larkin CM, Santos-Martinez MJ, Ryan T, Radomski MW. Sepsis-associated thrombocytopenia. Thromb Res. 2016;141:11-6.

7. Speck ER, Kim M, Crow AR, Bang KA, Nestel FP, et al. Platelet toll-like receptor expression modulates lipopolysaccharide-induced thrombocytopenia and tumor necrosis factor-alpha production in vivo. Blood. 2006;107:637-41. 
8. Camerer E, Cornelissen I, Kataoka H, Duong DN, Zheng YW, Coughlin SR, et al. Roles of proteaseactivated receptors in a mouse model of endotoxemia. Blood. 2006; 107:3912-21.

9. François B, Trimoreau F, Vignon P, Fixe P, Praloran V, Gastinne H. Thrombocytopenia in the sepsis syndrome: Role of hemophagocytosis and macrophage colony-stimulating factor. Am J Med. 1997;103:114-20.

10. Iba T, Watanabe E, Umemura Y, Fixe P, Praloran V, Gastinne H, et al. Sepsis-associated disseminated intravascular coagulation and its differential diagnoses. J Intensive Care. 2019;7:32.

11. Schwertz H, Köster S, Kahr WH, Michetti N, Kraemer BF, Weitz DA, et al. Anucleate platelets generate progeny. Blood. 2010;115:3801-9.

12. Taylor FB, Toh $\mathrm{CH}$, Hoots WK, Wada H, Levi M. Towards definition, clinical and laboratory criteria, and a scoring system for disseminated intravascular coagulation. Thromb Haemost. 2001;86:1327-30.

13. Gando S, Iba T, Eguchi Y, Ohtomo Y, Okamoto K, Koseki K, et al. A multicenter, prospective validation of disseminated intravascular coagulation diagnostic criteria for critically ill patients: Comparing current criteria. Crit Care Med. 2006;34:625-31.

14. Iba T, Di Nisio M, Levy JH, Kitamura N, Thachil J. New criteria for sepsis-induced coagulopathy (SIC) following the revised sepsis definition: A retrospective analysis of a nationwide survey. BMJ Open. 2017;7:e017046.

15. Lyons PG, Micek ST, Hampton N, Kollef MH. Sepsis-associated coagulopathy severity predicts hospital mortality. Crit Care Med. 2018;46:736-42.

16. Moreau D, Vesin A, Garrouste-Orgeas M. Platelet count decline: An early prognostic marker in critically ill patients with prolonged ICU stays. Chest. 2007;131:1735-41.

17. Pollard TJ, Johnson AE, Raffa JD, Celi LA, Mark RG, Badawi O. The elCU collaborative research database, a freely available multi-center database for critical care research. Sci Data. 2018;5:180178.

18. Angus DC, Linde-Zwirble WT, Lidicker J, Clermont G, Carcillo J, Pinsky MR. Epidemiology of severe sepsis in the United States: analysis of incidence, outcome, and associated costs of score. Crit Care Med. 2001;29:1303-10.

19. Benchimol El, Smeeth L, Guttmann A, Harron K, Moher D, Petersen I. The reporting of studies conducted using observational routinely-collected health data (RECORD) statement. PLoS Med. 2015;2:e1001885.

20. Brakenridge SC, Efron PA, Stortz JA, Ozrazgat-Baslanti T, Ghita G, Wang Z, et al. The impact of age on the innate immune response and outcomes after severe sepsis/septic shock in trauma and surgical intensive care unit patients. J Trauma Acute Care Surg. 2018;85:247-55.

21. Pepper DJ, Demirkale CY, Sun J, Rhee C, Fram D, Eichacker P, et al. Does obesity protect against death in sepsis? A retrospective cohort study of 55,038 adult patients. Crit Care Med. 2019;47:64350 .

22. Patel P, Walborn A, Rondina M, Fareed J, Hoppensteadt D. Markers of inflammation and infection in sepsis and disseminated intravascular coagulation. Clin Appl Thromb Hemost. 2019; 25:1076029619843338. 
23. McDonald B, Davis RP, Kim SJ, Tse M, Esmon CT, Kolaczkowska E, et al. Platelets and neutrophil extracellular traps collaborate to promote intravascular coagulation during sepsis in mice. Blood. 2017;129:1357-67.

24. Vail E, Gershengorn HB, Hua M, Walkey AJ, Rubenfeld G, Wunsch H, et al. Association between us norepinephrine shortage and mortality among patients with septic shock. JAMA. 2017;317:1433-42.

25. Begg MD, Parides MK. Separation of individual-level and cluster-level covariate effects in regression analysis of correlated data. Stat Med. 2003;22:2591-2602.

26. Enders CK, Tofighi D. Centering predictor variables in cross-sectional multilevel models: a new look at an old issue. Psychol Methods. 2007;12:121-38.

27. Zhang Z. Multiple imputation with multivariate imputation by chained equation (MICE) package. Ann Transl Med. 2016;4:30.

28. Johnson AE, Aboab J, Raffa JD, Pollard TJ, Deliberato RO, Celi LA, et al. A comparative analysis of sepsis identification methods in an electronic database. Crit Care Med. 2018;46:494-9.

29. Moreau D, Vesin A, Garrouste-Orgeas M, de Lassence A, Zahar JR, Adrie C, et al. Platelet count decline: An early prognostic marker in critically ill patients with prolonged ICU stays. Chest. 2007;131:1735-41.

30. Semeraro F, Colucci M, Caironi P, Masson S, Ammollo CT, Teli R, et al. Platelet drop and fibrinolytic shutdown in patients with sepsis. Crit Care Med. 2018; 46:e221-8.

31. Force AD, Ranieri VM, Rubenfeld GD, Thompson BT, Ferguson ND, Caldwell E. Acute respiratory distress syndrome: The Berlin definition. JAMA. 2012;307:2526-33.

32. Guérin C, Reignier J, Richard JC, Beuret P, Gacouin A, Boulain T, et al. Prone positioning in severe acute respiratory distress syndrome. N Engl J Med. 2013; 368:2159-68.

33. Seymour CW, Kennedy JN, Wang S, Chang CC, Elliott CF, Xu Z, et al. Derivation, validation, and potential treatment implications of novel clinical phenotypes for sepsis. JAMA. 2019; 321:2003-17.

\section{Tables}

Table 1 Baseline characteristics 


\begin{tabular}{|c|c|}
\hline Total & 26193 \\
\hline Male sex, n (\%) & $13539(51.7)$ \\
\hline Age, years, mean (SD) & $66.16(15.4)$ \\
\hline Admission weight, kg, mean (SD) & $84.07(29.5)$ \\
\hline \multicolumn{2}{|l|}{ Ethnicity, n (\%) } \\
\hline Caucasian & $20393(77.8)$ \\
\hline African American & $2753(10.5)$ \\
\hline Asian & $418(1.6)$ \\
\hline Hispanic & $1064(4.1)$ \\
\hline Native American & $216(0.8)$ \\
\hline Other/Unknown & $1363(5.2)$ \\
\hline \multicolumn{2}{|l|}{ Focus of infection, n (\%) } \\
\hline Abdominal & $3601(13.7)$ \\
\hline Pulmonary & $13635(52.0)$ \\
\hline Soft tissue & $1752(6.7)$ \\
\hline Urinary tract & $3925(15.0)$ \\
\hline Others/unknown & $3294(12.6)$ \\
\hline Charlson comorbidity index, median (IQR) & $4(2-6)$ \\
\hline SOFA score on admission, median (IQR) & $7[5-10]$ \\
\hline APACHE IV score, median (IQR) & $3370(12.9)$ \\
\hline Platelet count (day 1 ), $\times 10^{3} / \mu \mathrm{L}$, median (IQR) & $181(125-251)$ \\
\hline Platelet count (day 2 ), $\times 10^{3} / \mu \mathrm{L}$, median (IQR) & $174(117-242)$ \\
\hline \multicolumn{2}{|l|}{ Treatment on day $1, \mathrm{n}(\%)$} \\
\hline Mechanical ventilation & $1925(7.3)$ \\
\hline Renal replacement therapy & $1109(4.2)$ \\
\hline \multicolumn{2}{|c|}{ New coagulopathy-related complications after day2 of ICU admission, n (\%) } \\
\hline Hemorrhage & $145(0.6)$ \\
\hline Thrombosis & $139(0.5)$ \\
\hline In-hospital death, n (\%) & 4885 (16.7) \\
\hline
\end{tabular}


SD, standard deviation; IQR, interquartile range; SOFA, sequential organ failure assessment; APACHE, acute physiology and chronic health evaluation

Table 2. Association of relative platelet reduction and platelet counts with in-hospital mortality for patients with sepsis. 


\begin{tabular}{|c|c|c|c|}
\hline Cohort & $\begin{array}{l}\text { Crude Odds ratio } \\
(95 \% \mathrm{Cl})\end{array}$ & $\begin{array}{l}\text { Adjusted odds ratio } \\
(95 \% \mathrm{Cl})^{a}\end{array}$ & $\begin{array}{l}\mathrm{P} \\
\text { Value }\end{array}$ \\
\hline \multicolumn{4}{|l|}{ Primary cohort } \\
\hline \multicolumn{4}{|l|}{ Relative platelet reduction (\%) } \\
\hline$<20$ & reference & reference & \\
\hline $20-40$ & $1.69(1.64-1.74)$ & $1.28(1.23-1.32)$ & $<0.001$ \\
\hline $40-60$ & $2.98(2.83-3.15)$ & $1.86(1.75-1.97)$ & $<0.001$ \\
\hline $60-80$ & $5.47(4.94-6.05)$ & $2.99(2.66-3.36)$ & $<0.001$ \\
\hline$\geqq 80$ & $13.56(10.29-17.98)$ & $6.05(4.40-8.31)$ & $<0.001$ \\
\hline Absolute platelet count on day $2^{b}$ & $1.29(1.27-1.30)$ & $1.20(1.18-1.21)$ & $<0.001$ \\
\hline \multicolumn{4}{|l|}{$\begin{array}{l}\text { Patient without resultant } \\
\text { thrombocytopenia }{ }^{c}\end{array}$} \\
\hline \multicolumn{4}{|l|}{ Relative platelet reduction (\%) } \\
\hline$<20$ & reference & reference & \\
\hline $20-40$ & $1.70(1.64-1.76)$ & $1.30(1.24-1.36)$ & $<.001$ \\
\hline $40-60$ & $2.48(2.32-2.65)$ & $1.64(1.48-1.82)$ & $<.001$ \\
\hline $60-80$ & $4.88(4.26-5.58)$ & $3.10(2.30-4.17)$ & $<.001$ \\
\hline$\geqq 80$ & $12.82(8.95-18.50)$ & $0.52(0.06-4.28)$ & 0.55 \\
\hline Absolute platelet count on day $2^{b}$ & $1.03(0.99-1.06)$ & $0.97(0.94-1.00)$ & 0.07 \\
\hline \multicolumn{4}{|l|}{$\begin{array}{l}\text { Patient with resultant } \\
\text { thrombocytopenia }{ }^{c}\end{array}$} \\
\hline \multicolumn{4}{|l|}{ Relative platelet reduction (\%) } \\
\hline$<20$ & reference & reference & \\
\hline $20-40$ & $1.59(1.48-1.70)$ & $1.17(1.10-1.25)$ & $<.001$ \\
\hline $40-60$ & $3.46(3.16-3.79)$ & $1.69(1.56-1.83)$ & $<.001$ \\
\hline $60-80$ & $4.78(4.08$ - 5.59) & $2.47(2.15-2.83)$ & $<.001$ \\
\hline$\geqq 80$ & $16.46(10.10-28.00)$ & $6.55(4.54-9.46)$ & $<.001$ \\
\hline Absolute platelet count on day $2^{b}$ & $1.59(1.53-1.65)$ & $1.38(1.32-1.44)$ & $<.001$ \\
\hline \multicolumn{4}{|l|}{ Patient with shock ${ }^{d}$} \\
\hline Relative platelet reduction (\%) & & & \\
\hline
\end{tabular}




\begin{tabular}{|llll|}
\hline$<20$ & reference & reference & \\
\hline $20-40$ & $1.32(1.26-1.39)$ & $1.13(1.07-1.19)$ & $<.001$ \\
\hline $40-60$ & $2.13(1.98-2.30)$ & $1.59(1.45-1.73)$ & $<.001$ \\
\hline $60-80$ & $3.30(2.83-3.83)$ & $2.26(1.89-2.71)$ & $<.001$ \\
\hline$\geqq 80$ & $6.90(4.83-9.91)$ & $4.82(3.16-7.34)$ & $<.001$ \\
\hline Absolute platelet count on day 2 ${ }^{\mathrm{b}}$ & $1.22(1.20-1.25)$ & $1.14(1.12-1.17)$ & $<.001$ \\
\hline Patient with respiratory failure ${ }^{\mathrm{e}}$ & & & \\
\hline Relative platelet reduction $(\%)$ & & & $<.001$ \\
\hline$<20$ & reference & reference & $<.001$ \\
\hline $20-40$ & $1.63(1.55-1.71)$ & $1.18(1.12-1.25)$ & $<.001$ \\
\hline $40-60$ & $2.46(2.26-2.67)$ & $1.36(1.23-1.50)$ & $<.001$ \\
\hline $60-80$ & $4.86(4.19-5.64)$ & $2.13(1.79-2.54)$ & $<.001$ \\
\hline$\geqq 80$ & $12.37(8.36-18.67)$ & $9.21(5.79-14.66)$ & \\
\hline Absolute platelet count on day2 ${ }^{\mathrm{b}}$ & $1.36(1.33-1.38)$ & $1.24(1.21-1.27)$ & \\
\hline
\end{tabular}

Cl, Confidence interval; SOFA, Sequential Organ Failure Assessment.

a Variables in the model included patient age, sex, race, Charlson comorbidity index, relative platelet reduction, absolute platelet count on day 2, Acute Physiology and Chronic Health Evaluation (APACHE) IV score, focus of infection, body mass index, nosocomial onset, number of ICU visit, types of unit, region, teaching status, and hospital bed size. Hospital admission as a random intercept to account for clustering by hospital.

${ }^{b}$ Categorized based on Hematology component of SOFA score

${ }^{\mathrm{c}}$ Defined as platelet count $\leqq 100 \times 10^{3} / \mu \mathrm{L}$ on day 2

${ }^{d}$ Defined as circulatory component of SOFA score $\geqq 3$

${ }^{\mathrm{e}}$ Defined as respiratory component of SOFA score $\geqq 3$

Table 3. Results of multivariate logistic regression analysis for predicting coagulopathy-related complications. 


\begin{tabular}{|c|c|c|c|}
\hline & $\begin{array}{l}\text { Crude Odds ratio } \\
(95 \% \mathrm{Cl})\end{array}$ & $\begin{array}{l}\text { Adjusted odds ratio } \\
(95 \% \mathrm{Cl})^{\mathrm{a}}\end{array}$ & $\begin{array}{l}P \\
\text { value }\end{array}$ \\
\hline \multicolumn{4}{|l|}{ For composite outcome } \\
\hline Relative platelet decrease $\geqq 50 \%$ & $3.40(2.84-4.05)$ & $2.03(1.68-2.45)$ & $<0.001$ \\
\hline $\begin{array}{l}\text { Platelet count } \leqq 100 \times 10^{3} / \mu \mathrm{L} \text { on } \\
\text { day } 2\end{array}$ & $1.63(1.50-1.78)$ & $1.18(1.07-1.30)$ & $<0.001$ \\
\hline \multicolumn{4}{|l|}{ For thrombotic events } \\
\hline Relative platelet decrease $\geqq 50 \%$ & $1.86(1.33-2.51)$ & $1.43(1.03-1.98)$ & 0.035 \\
\hline $\begin{array}{l}\text { Platelet count } \leqq 100 \times 10^{3} / \mu \mathrm{L} \text { on } \\
\text { day } 2\end{array}$ & $1.16(1.02-1.32)$ & $0.94(0.82-1.08)$ & 0.396 \\
\hline \multicolumn{4}{|l|}{ For hemorrhagic events } \\
\hline Relative platelet decrease $\geqq 50 \%$ & $4.82(3.91-5.88)$ & $2.35(1.89-2.93)$ & $<0.001$ \\
\hline $\begin{array}{l}\text { Platelet count } \leqq 100 \times 10^{3} / \mu \mathrm{L} \text { on } \\
\text { day } 2\end{array}$ & $2.06(1.84-2.30)$ & $1.27(1.12-1.44)$ & $<0.001$ \\
\hline
\end{tabular}

$\mathrm{Cl}$, Confidence interval.

Variables in the model included patient age, sex, race, Charlson comorbidity index, relative platelet reduction, absolute platelet count on day2, Acute Physiology and Chronic Health Evaluation (APACHE) IV score, focus of infection, body mass index.

\section{Figures}




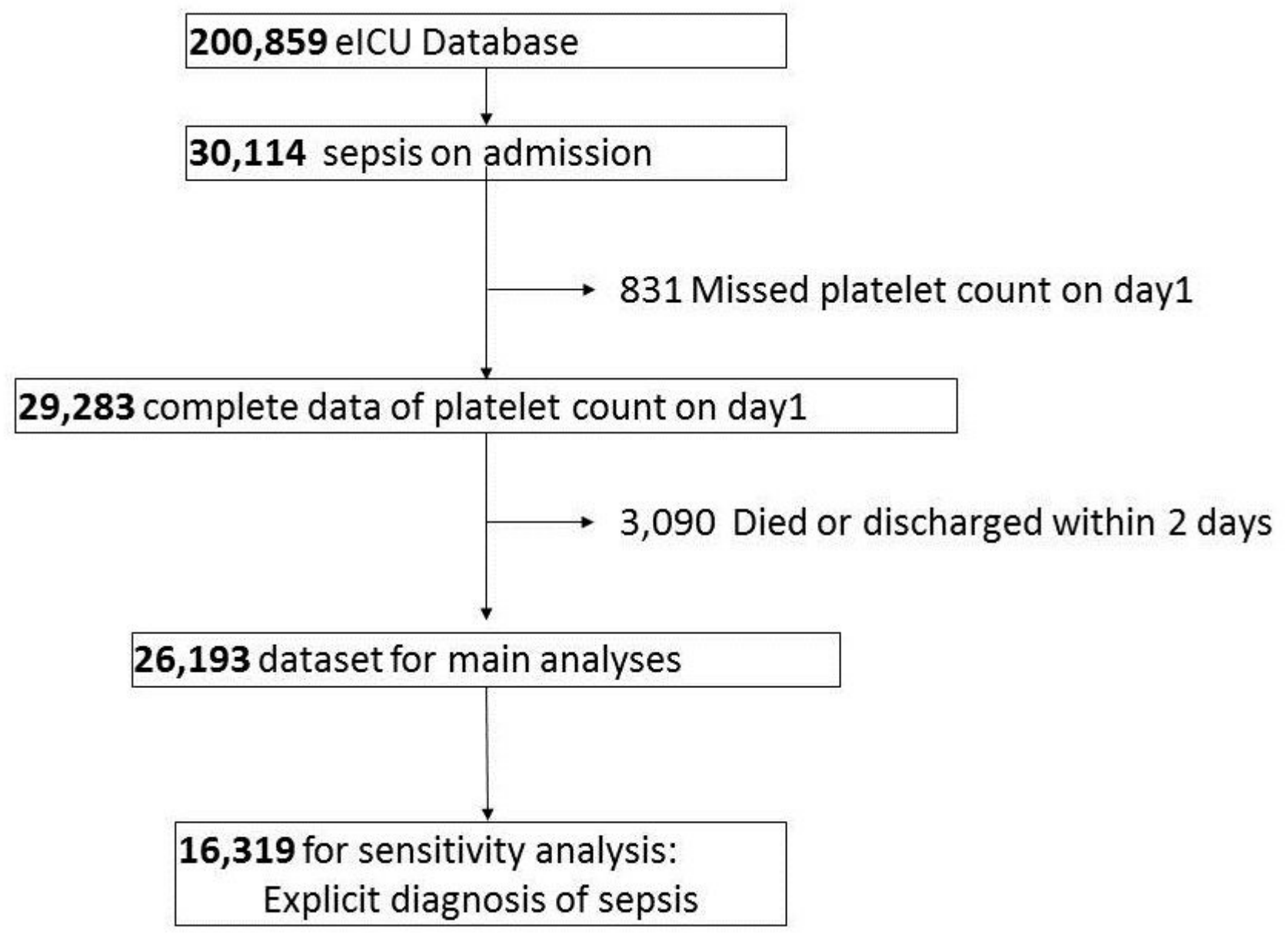

Figure 1

Flow diagram of patient selection

\section{Supplementary Files}

This is a list of supplementary files associated with this preprint. Click to download.

- additionalfile1.docx

- Additionalfile2.docx

- additionalfile3.docx 